\title{
Two Cases of Focal Scrotal Vitiligo Successfully Treated by Autologous Cultured Melanocyte Transplantation
}

\author{
Xiaowen $\mathrm{Li} \cdot$ Weisong Hong $\cdot$ Ai-E Xu
}

To view enhanced content go to www.dermtherapy-open.com Received: February 10, 2014 / Published online: March 27, 2014

(c) The Author(s) 2014. This article is published with open access at Springerlink.com

\begin{abstract}
Vitiligo is an acquired cutaneous depigmentation disorder which has a deleterious effect on the psychosexual function of many individuals; the genitalia are the common site for depigmentation. Here, the authors report two cases of focal vitiligo affecting the scrotum of the genital organs which were successfully treated by autologous cultured melanocyte transplantation. Autologous cultured melanocyte transplantation on the scrotum is shown to be a relative effective method of treatment for vitiligo.
\end{abstract}

Electronic supplementary material The online version of this article (doi:10.1007/s13555-014-0050-5) contains supplementary material, which is available to authorized users.

X. Li · W. Hong · A.-E. Xu ( $\varangle)$

Department of Dermatology, Third People's

Hospital of Hangzhou, The 2nd Affiliated Clinical

Medical College, Zhejiang Chinese Medical

University, Hangzhou, China

e-mail: xuaiehz@msn.com

$\mathrm{X}$. Li

e-mail: 13293900584@163.com
Keywords: Autologous cultured melanocyte transplantation;

Dermatology;

Repigmentation; Scrotal vitiligo

\section{INTRODUCTION}

Vitiligo is an acquired cutaneous depigmentation disorder, which has a deleterious effect on the psychosexual function of many individuals; the genitalia are the common site for depigmentation [1]. There are few reports about treatment of genital vitiligo [2-5]. Only one report discovered by the authors refers to depigmentation of the scrotum [5]. The importance of follicles as a reservoir of melanocytes is emphasized by the well-known fact that glabrous skin (i.e., non-hair-bearing skin), such as genitalia, rarely responds to therapy unless it has some residual pigment [6]. Therefore, the treatment of genital vitiligo is difficult. Here, the authors report two cases of focal vitiligo affecting the scrotum of the genital organs which were successfully treated by autologous cultured melanocyte transplantation.

\section{METHODS}

Donor skin was obtained from the patients' normally pigmented area of the abdomen or 
thighs. Specimens were washed with calciumfree Hanks' solution, incubated in $0.25 \%$ trypsin solution for $10 \mathrm{~min}$, followed by incubation with $0.02 \%$ ethylenediaminetetraacetic acid (EDTA) solution for $10 \mathrm{~min}$ at $37^{\circ} \mathrm{C}$. Cells were separated from the epidermal sheet under a stereomicroscope. The cell suspension was centrifuged, re-suspended with Hu16 medium (F12 medium with $20 \mathrm{ng} / \mathrm{ml}$ basic fibroblast growth factor, $20 \mu \mathrm{g} / \mathrm{ml} \quad 3$-isobutyl-1methylxanthine, $10 \mathrm{ng} / \mathrm{ml}$ cholera toxin, $50 \mu \mathrm{g}$ / $\mathrm{ml}$ gentamicin, and $10 \%$ fetal bovine serum) and seeded into a culture flask. Cells were incubated in a humidified $5 \% \mathrm{CO}_{2}$ atmosphere at $37^{\circ} \mathrm{C}$. Geneticin (Sigma-Aldrich, Saint Louis, MO, USA) was added to the medium $(100 \mu \mathrm{g} / \mathrm{ml}) 3$ days later to eliminate contaminating cells. After primary cultures became confluent, the melanocytes were detached by $0.125 \%$ trypsin/ $0.01 \%$ EDTA solution, centrifuged, resuspended, diluted at a ratio of 1:2-1:3, and seeded into culture flasks for subculture. After the cell number met the requirement for transplantation (approximately 80,000 melanocytes $/ \mathrm{cm}^{2}$ ), the melanocytes were detached as described above, centrifuged, resuspended in F12 medium, and transferred to the operating room for transplantation in a timely manner.

A topical anesthetic, lidocaine cream, was applied $2-4 \mathrm{~h}$ before transplantation. The recipient areas were cleaned with 70\% alcohol and treated with UltraPulse ${ }^{\circledR} \quad \mathrm{CO}_{2}$ laser (Lumenis, Santa Clara, CA, USA; pulse rate $30-50 \mathrm{~Hz}$ at an energy level of $225 \mathrm{~mJ}$ per pulse) to remove the epidermis. The melanocyte suspension was applied to the laser-denuded area with a pipette at a density of 80,000 melanocytes $/ \mathrm{cm}^{2}$. The recipient site was immediately covered with silicone gauze, followed by a gauze-soaked in F12 culture medium, and, finally, secured with Tegaderm
(3 M Health Care Ltd, Laughborough, UK) and surgical tape. After the procedure, patients were instructed to recline flat for at least $1 \mathrm{~h}$ to allow successful attachment of the melanocytes to the recipient site. The patient was cautioned against any vigorous activities, which could displace the dressing. All dressings were removed 7-10 days later.

The Ethical Committee of the National Center for Vitiligo and Psoriasis approved the treatment. The study was approved by the institutional review Board of Third People's Hospital of Hangzhou, and written informed consent was obtained from each patient for inclusion in this study and for publication of the photographs. All procedures followed were in accordance with the ethical standards of the Helsinki Declaration of 1975, as revised in 2000 and 2008.

\section{CASE REPORTS}

\section{Case 1}

A 21-year-old male reported focal vitiligo of 5 years duration affecting the scrotum of the genital organ. The lesion was non-progressive for about 4 years. Physical examination revealed that the depigmentation patch affecting the scrotum had a total area of $20 \mathrm{~cm}^{2}$. The patient received the cultured autologous melanocytes transplantation in November 2011. The donor/ recipient size ratio (DOT) of the melanocytes was 3.46, and the concentration of melanocytes applied to the recipient area was $0.197 \mathrm{ng} /$ cell. Eighteen months post-transplantation, the vitiliginous area of the scrotum was almost completely repigmented (Fig. 1). The depigmented lesion had not received phototherapy before or after transplantation, and the patient was very satisfied with the cosmetic results. 


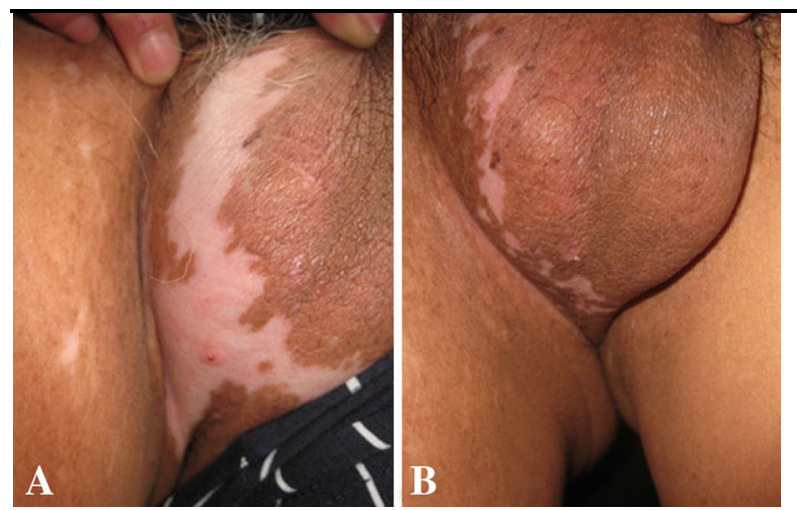

Fig. 1 Vitiligo lesion $\left(20 \mathrm{~cm}^{2}\right)$ in a 21-year-old male before (a) and 18 months after (b) the transplantation of autologous cultured melanocytes. A 90\% repigmentation was achieved

\section{Case 2}

A 16-year-old male was first received in September 2012 complaining of a depigmented lesion on the scrotum with a duration of 3 years. The lesion had not shown any progress in the last 2 years. The area of the lesions was $15 \mathrm{~cm}^{2}$. The patient had no family history of vitiligo. He failed to respond to medical treatment administered to him (topical pimecrolimus used for 6 months, twice daily). The patient underwent transplantation in September 2012. The DOT of the melanocytes was 3.24, and the concentration of melanocytes applied to the recipient area was $0.186 \mathrm{ng} / \mathrm{cell}$. In the latest follow-up in September 2013, the authors found the lesion 95\% repigmentation was achieved, and the patient was very satisfied with the cosmetic results (Fig. 2).

\section{DISCUSSION}

The genital is a commonly affected site for vitiligo in men, and it is sometimes the only site affected [7]. The treatment of genital vitiligo is quite complex. There are very few reports in the literature for the treatment of genital vitiligo.
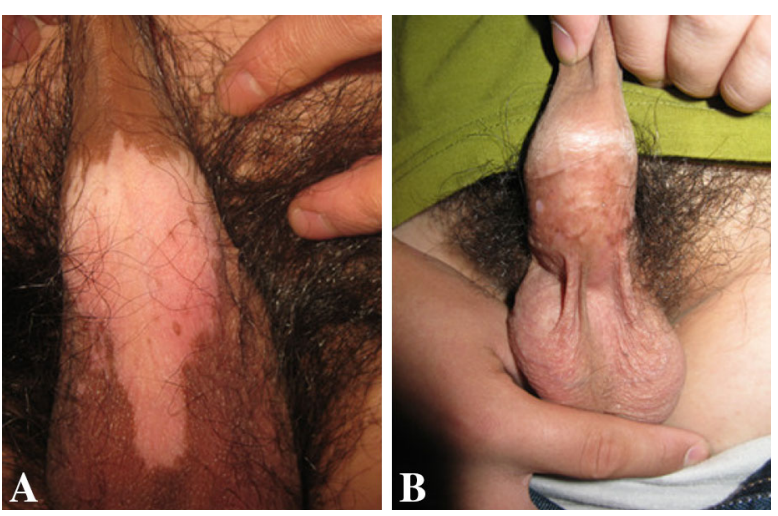

Fig. 2 Vitiligo lesion $\left(15 \mathrm{~cm}^{2}\right)$ in a 16-year-old male before (a) and 12 months after (b) the transplantation of autologous cultured melanocytes. A 95\% repigmentation was achieved

Souza Leite et al. [4] reported one case of genital vitiligo successfully treated by pimecrolimus. However, this patient had a short duration of the disease considering the existence of residual melanocytes. Therefore, the use of medication was considered to be a better option. For vitiligo with longer duration or vitiligo without residual pigment in genitals, surgical intervention is recommended. Mulekar et al. [3] reported three cases of focal vitiligo affecting the glans and shaft of the penis successfully treated by antilogous non-cultured melanocytekeratinocyte cell transplantation. Differing from their cases, the current transplantation site is located on the scrotum, and the scheme used was autologous cultured melanocyte transplantation. Mulekar et al. [3] needed to perform two rounds of surgery to achieve satisfying repigmentation, whereas the current authors achieved 90\% repigmentation in case 1 . Redondo et al. [5] used a graft of autologous melanocytes cultured on a denuded amniotic membrane to treat a patient with a scrotal lesion and achieved good regimentation. However, the current study did not use a denuded amniotic membrane, and achieved the same effect. 
Patients with genital vitiligo often hide their lesions, and postpone their complaints until they miss the best time for treatment with medication. Therefore, the development of surgical interventions is particularly important for the patients with long duration vitiligo. The current study indicates that autologous cultured melanocyte cell transplantation not only provides an opportunity for patients with large areas of stable vitiligo, but can also be used as a very effective treatment for genital vitiligo, including the scrotum.

\section{ACKNOWLEDGMENTS}

No funding or sponsorship was received for this study or publication of this article. All named authors meet the ICMJE criteria for authorship for this manuscript, take responsibility for the integrity of the work as a whole, and have given final approval for the version to be published.

Conflict of interest. Xiaowen Li, Weisong Hong, and Ai-E Xu have declared that they have no competing interests.

Compliance with ethics guidelines. The Ethical Committee of the National Center for Vitiligo and Psoriasis approved the treatment. The study was approved by the institutional review Board of Third People's Hospital of Hangzhou, and written informed consent was obtained from each patient for inclusion in this study and for publication of the photographs. All procedures followed were in accordance with the ethical standards of the Helsinki Declaration of 1975, as revised in 2000 and 2008.

Open Access. This article is distributed under the terms of the Creative Commons Attribution Noncommercial License which permits any noncommercial use, distribution, and reproduction in any medium, provided the original author(s) and the source are credited.

\section{REFERENCES}

1. Moss TR, Stevenson CJ. Incidence of male genital vitiligo. Report of a screening programme. $\mathrm{Br} \mathrm{J}$ Venereal Dis. 1981;57(2):145-6.

2. Olsson MJ, Juhlin L. Transplantation of melanocytes in vitiligo. Br J Dermatol. 1995;132(4):587-91.

3. Mulekar SV, Al Issa A, Al Eisa A, Asaad M. Genital vitiligo treated by autologous, noncultured melanocyte-keratinocyte cell transplantation. Dermatol Surg. 2005;31(12):1737-9.

4. Souza Leite RM, Craveiro Leite AA. Two therapeutic challenges: periocular and genital vitiligo in children successfully treated with pimecrolimus cream. Int J Dermatol. 2007;46(9):986-9.

5. Redondo P, del Olmo J, García-Guzman M, Guembe L, Prósper F. Repigmentation of vitiligo by transplantation of autologous melanocyte cells cultured on amniotic membrane. Br J Dermatol. 2008;58(5):1134-73.

6. Anbar T, Hegazy R, Picardo M, Taieb A. Beyond vitiligo guidelines: combined stratified/personalized approaches for the vitiligo patient. Exp Dermatol. 2014. doi:10.1111/exd.12344. (Epub ahead of print).

7. Bunker CB. Non-venereal penile dermatoses. In: Kumar B, Gupta S, editors. Sexually transmitted infections. New Delhi: Elsevier; 2005. p. 539-64. 